Article

\title{
An Enantioselective Potentiometric Sensor for 2-Amino-1-Butanol Based on Chiral Porous Organic Cage CC3-R
}

\author{
Bang-Jin Wang ${ }^{1,2}$, Ai-Hong Duan ${ }^{2}$, Jun-Hui Zhang ${ }^{2}$, Sheng-Ming Xie ${ }^{2}$, Qiu-E Cao ${ }^{1, *}$ and \\ Li-Ming Yuan ${ }^{2, *}$ \\ 1 Key Laboratory of Medicinal Chemistry for Natural Resource, Ministry of Education, School of Chemical \\ Science and Technology, Yunnan University, Kunming 650091, China; wangbangjin711@163.com \\ 2 Department of Chemistry, Yunnan Normal University, Kunming 650500, China; \\ duanaihong215@aliyun.com (A.-H.D.); zjh19861202@126.com (J.-H.Z.); \\ xieshengming_2006@163.com (S.-M.X.) \\ * Correspondence: qecao@ynu.edu.cn (Q.-E.C.); yuan_limingpd@126.com (L.-M.Y.); \\ Tel./Fax: +86-871-6503-3679 (Q.-E.C.); +86-871-6594-1088 (L.-M.Y.)
}

Received: 23 December 2018; Accepted: 23 January 2019; Published: 24 January 2019

\begin{abstract}
Porous organic cages (POCs) have attracted extensive attention due to their unique structures and tremendous application potential in numerous areas. In this study, an enantioselective potentiometric sensor composed of a polyvinyl chloride (PVC) membrane electrode modified with CC3-R POC material was used for the recognition of enantiomers of 2-amino-1-butanol. After optimisation, the developed sensor exhibited enantioselectivity toward S-2-amino-1-butanol $\left(\log K_{S, R}^{P o t}=-0.98\right)$ with acceptable sensitivity, and a near-Nernstian response of $25.8 \pm 0.3 \mathrm{mV} /$ decade within a pH range of 6.0-9.0.
\end{abstract}

Keywords: enantioselective potentiometric sensor; 2-amino-1-butanol; chiral porous organic cage; CC3-R; PVC membrane electrode

\section{Introduction}

Chirality is a general phenomenon and an important characteristic in naturally occurring molecules. For instance, most amino acids are levorotatory and sugars are dextrorotatory in biological systems. Consequently, chiral discrimination has attracted tremendous attention on account of its significance in pharmaceutical, biomedicine and chemical fields. Currently, chiral discrimination can be precisely achieved in many ways including gas chromatography (GC), high-performance liquid chromatography (HPLC) and high-performance capillary electrophoresis (HPCE). Although these methods have different advantages in terms of sensitivity or applicability, they suffer similar drawbacks including complicated operation and the need for expensive equipment. By contrast, ion-selective electrodes are simple, rapid and affordable, and have been widely applied to the enantioselective recognition and detection of chiral compounds in recent years [1-9].

As versatile functional material platforms, porous organic cages (POCs) have attracted much attention [10-13], and have been widely applied in various areas such as gas-selective adsorption and separation [14-17], molecular recognition [18-27], catalysis [28], water treatment [29] and sensing [30]. As shown in Figure 1, the R-type chiral POC CC3-R has an interlinked chiral pore channel structure with adjacent tetrahedral cages packed together [31,32]. The chiral pore channel structures and cyclohexyl, imino and phenyl groups of cage molecules constitute a chiral microenvironment comprising a variety of enantioselective factors including dispersion forces, dipolar interactions and hydrogen bonds [33]. These properties combine to make CC3-R an excellent chiral selector for use in chiral recognition 
methods. Recently, a CC3-R-modified GC stationary phase was developed for the separation of racemates, and exhibited excellent enantioselectivity [34].
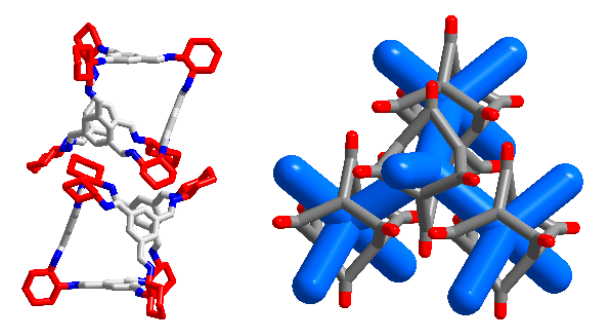

Figure 1. Schematic diagram of the structure of CC3-R.

2-Amino-1-butanol (Figure 2) is generally used as an intermediate in the synthesis of pharmaceuticals such as the bacteriostatic antituberculosis agent $(S, S)$-ethambutol [35-38]. In the present work, CC3-R was applied as a chiral selector in PVC membrane electrodes, resulting in impressive enantioselectivity for S-2-amino-1-butanol. Factors influencing the enantioselectivity of the CC3-R-based membrane electrode, such as the content of CC3-R, the category of plasticiser and the $\mathrm{pH}$ value of analyte solutions, were systematically investigated.

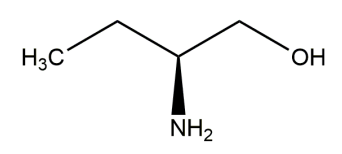

$S$-(+)-2-Amino-1-butanol

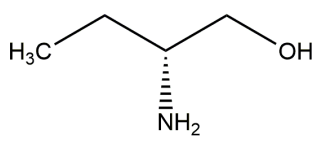

$R$-(-)-2-Amino-1-butanol

Figure 2. Molecular structure of 2-amino-1-butanol.

\section{Results and Discussion}

\subsection{Characterisation of the Synthesised CC3-R}

The synthesised CC3-R crystals were characterised by Nuclear Magnetic Resonance (NMR), Powder X-ray diffraction (PXRD) and elemental analysis. As can be seen in Figure 3, the PXRD pattern of synthesised CC3-R crystals was consistent with the Singlecrystal simulation. Furthermore, CC3-R retained the same crystallinity and structure whether recrystallised from tetrahydrofuran or rinsed with water for $48 \mathrm{~h}$, demonstrating excellent stability as chiral selector in the membrane electrode.

Elemental analysis was performed on CC3-R $\left(\mathrm{C}_{72} \mathrm{H}_{85} \mathrm{~N}_{12}\right)$; calculated = C 77.31, H 7.66, N 15.03; detected $=\mathrm{C} 77.08, \mathrm{H} 7.76, \mathrm{~N} 14.88 .{ }^{1} \mathrm{H}-\mathrm{NMR}\left(\mathrm{CDCl}_{3}\right) \delta=8.18(\mathrm{~s}, 12 \mathrm{H},-\mathrm{CH}=\mathrm{N}-), 7.92(\mathrm{~s}, 12 \mathrm{H},-\mathrm{Ar}-\mathrm{H})$, $3.36(\mathrm{~m}, 12 \mathrm{H},-\mathrm{CHN}-), 1.86-1.54\left(\mathrm{~m}, 48 \mathrm{H},-\mathrm{CH}_{2}-\right) \mathrm{ppm} .{ }^{13} \mathrm{C}-\mathrm{NMR}\left(\mathrm{CDCl}_{3}\right) \delta=159.15,136.64,129.53$, $74.65,33.02,24.39 \mathrm{ppm}$. All characterisation data confirmed that CC3-R was successfully synthesised.

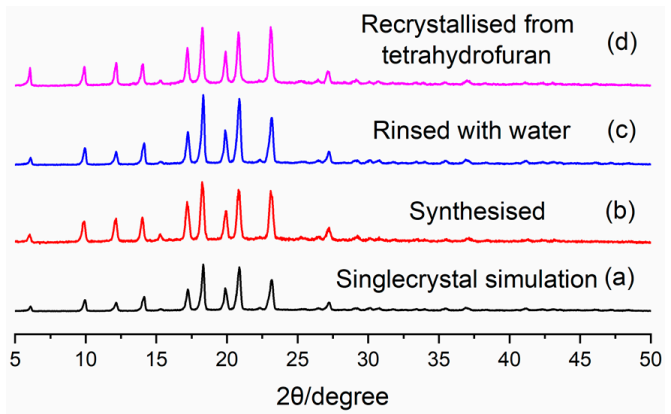

Figure 3. PXRD patterns of CC3-R: (a) Singlecrystal simulation, (b) synthesised, (c) rinsed with water for $48 \mathrm{~h}$, (d) recrystallised from tetrahydrofuran. 


\subsection{Optimisation of Membrane Components}

The nature and amount of chiral selector and plasticiser contained in the membrane can strongly influence the selectivity and sensitivity of the membrane electrode. Consequently, the potential response characteristics of multiple electrodes with different quantities of CC3-R and three types of plasticiser (o-NPOE, DOS and DBP) were evaluated.

Figure 4 shows the potential response characteristics of membrane electrodes with different CC3-R mass percentages. The performance of the membrane electrode improved with increasing CC3-R content, and the best enantioselectivity toward S-2-amino-1-butanol was achieved with 3\% CC3-R (by weight). However, the enantioselectivity and sensitivity decreased slightly when the amount of CC3-R reached 4\%. It is possible that the PVC membrane becomes saturated, hence the number of recognition sites does not increase proportionately with the chiral selector. Moreover, excess CC3-R could affect the ion-exchange capacity of the membrane electrode.

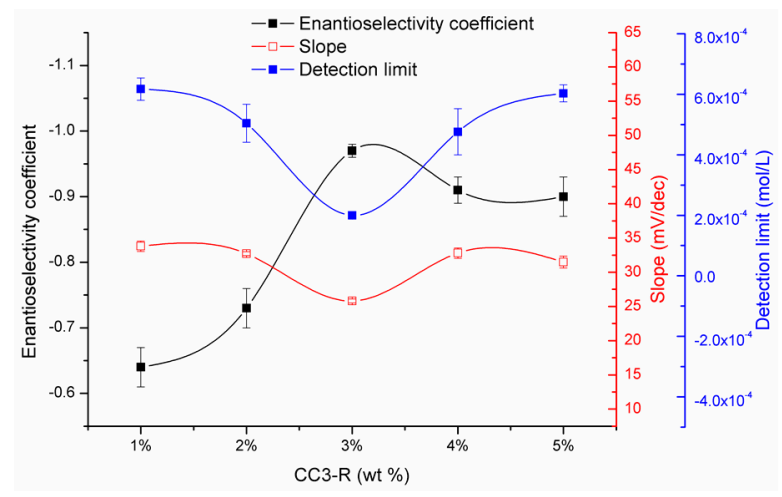

Figure 4. Potential response characteristics of membrane electrodes with different CC3-R contents.

The influence of the type of plasticiser is shown in Figure 5. DOS and DBP were clearly inferior to $o$-NPOE in terms of detection limit and enantioselectivity coefficient for S-2-amino-1-butanol.

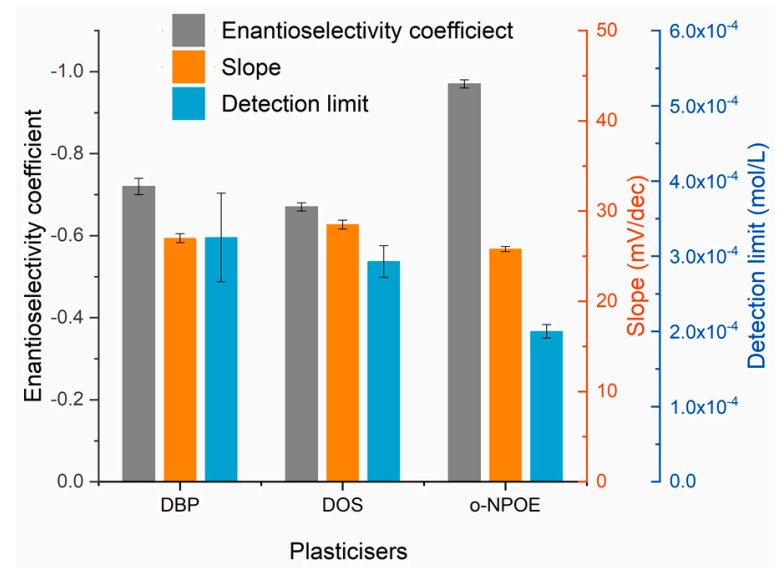

Figure 5. Potential response characteristics of membrane electrodes with different types of plasticiser.

\subsection{Effect of $p H$ on the Electrode}

In order to investigate the effect of $\mathrm{pH}$ on the response performance of the optimised membrane electrode, the potential response value of the 2-amino-1-butanol solution $\left(1.0 \times 10^{-3} \mathrm{~mol} \cdot \mathrm{L}^{-1}\right)$ was measured at different $\mathrm{pH}$ values $(\mathrm{pH}$ 2.0-12.0). As shown in Figure 6, the potential response value was stable within a $\mathrm{pH}$ range of 5.0-9.0. Furthermore, a large difference between the two enantiomers was observed at $\mathrm{pH}$ 9.0. Therefore, $\mathrm{pH} 9.0$ was adopted for measurements using the optimised membrane electrode. 


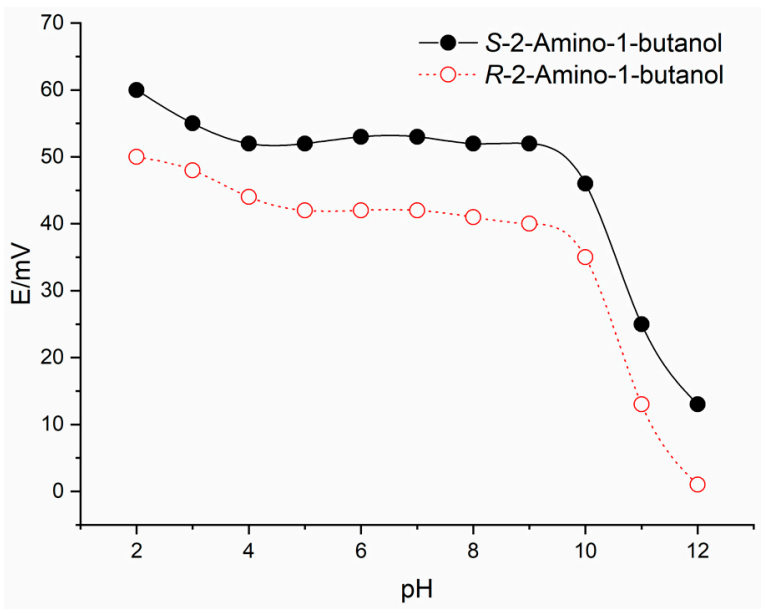

Figure 6. The influence of $\mathrm{pH}$ on the response performance of the membrane electrode to $S / R$-2-amino-1-butanol.

\subsection{Enantioselectivity Coefficient of the Electrode}

Figure 4 shows $\log K_{S, R}^{P o t}$ values for membrane electrodes of varying composition. The optimised membrane electrode containing $3 \mathrm{wt} \% \mathrm{CC} 3-\mathrm{R}$ displayed impressive enantioselectivity toward $S$-2-amino-1-butanol over $R$-2-amino-1-butanol ( $\left.\log K_{S, R}^{P o t}=-0.98\right)$. By comparison, the CC3-S ( $3 \mathrm{wt} \%$ ) modified membrane electrode showed similar enantioselectivity toward $R$-2-amino-1-butanol $\left(\log K_{S, R}^{\text {Pot }}=-0.94\right)$.

Furthermore, the $\log K_{S, \text { int }}^{\text {Pot }}$ value was used to evaluate the enantioselectivity of the optimised electrode in the presence of interfering ions with a similar configuration to 2-amino-1-butanol [39]. Specifically, the potential values of $R / S$-2-amino-3-phenyl-1-propanol, $R / S$-2-amino-3-methyl-1-butanol and $R / S$-3-amino-1,2-propanediol $\left(0.1 \mathrm{~mol} \cdot \mathrm{L}^{-1}\right)$ were measured, and $\log K_{S, \text { int }}^{\text {Pot }}$ values are shown in Table 1.

Table 1. $\log K_{S, \text { int }}^{\text {Pot }}$ values of ions potentially interfering with S-2-amino-1-butanol.

\begin{tabular}{cc}
\hline Interference Ion & Log $_{\text {S, int }}^{\text {Pot }}$ \\
\hline$R$-2-Amino-1-butanol & -0.98 \\
S-2-Amino-3-phenyl-1-propanol & -0.59 \\
R-2-Amino-3-phenyl-1-propanol & -0.59 \\
S-2-Amino-3-methyl-1-butanol & 0.31 \\
R-2-Amino-3-methyl-1-butanol & 0.26 \\
S-3-Amino-1,2-propanediol & -0.41 \\
R-3-Amino-1,2-propanediol & -0.41 \\
\hline
\end{tabular}

As shown in Table 1, the membrane electrode exhibited comparable responses to other alkamines with similar configurations to 2-amino-1-butanol. Steric hindrance caused by additional organic groups of other alkamines could impair the recognition performance during ion exchange. The electrode displayed slight enantioselective recognition of enantiomers of 2-amino-3-methyl-1-butanol, which have the most similar configuration. However, 2-amino-3-methyl-1-butanol yielded similar potential response values, and caused significant interference.

\subsection{Recognition of Mixing Samples}

To further explore the enantioselectivity of the developed membrane electrode, a mixing sample test was conducted using different molar ratios of $S$ - and $R$-enantiomers of 2-amino-1-butanol (Figure 7). The results showed that the potential response values of the mixing solution increased with increasing proportion of S-2-amino-1-butanol, revealing a clear positive linear correlation between the proportion 
of S-2-amino-1-butanol and potential response values of mixing solutions $\left(0.1 \mathrm{~mol} \cdot \mathrm{L}^{-1}\right)$. These results demonstrate the selective recognition of $S$-2-amino-1-butanol in the presence of $R$-2-amino-1-butanol.

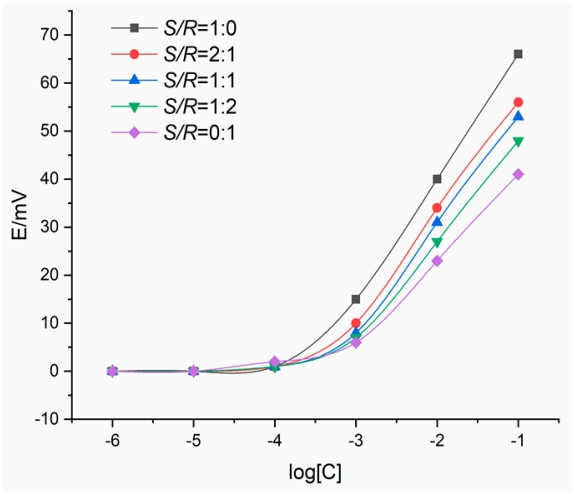

a

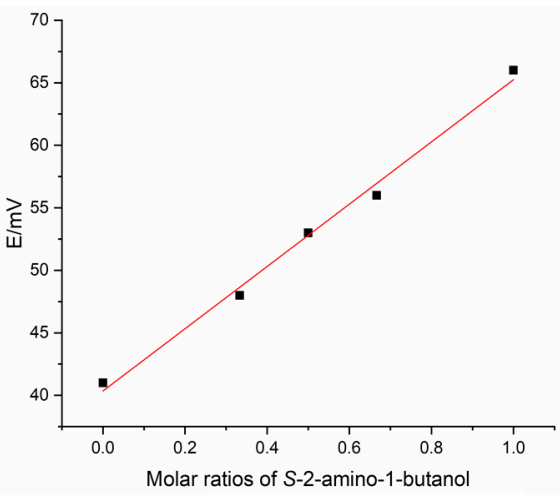

b

Figure 7. (a) Potential responses of $S$ - and $R$-enantiomers of 2-amino-1-butanol mixing solutions. (b) Positive linear correlation between the proportion of S-2-amino-1-butanol and potential response values of mixing solutions $\left(0.1 \mathrm{~mol} \cdot \mathrm{L}^{-1}\right)$.

\section{Materials and Methods}

\subsection{Materials}

Enantiomers of 2-amino-1-butanol, 2-amino-3-phenyl-1-propanol, 2-amino-3-methyl-1-butanol, and 3-amino-1,2-propanediol were obtained from Aladdin (Shanghai, China). $(R, R)-1,2-$ Diaminocyclohexane and 1,3,5-triformylbenzene were purchased from Acros (Geel, Belgium). o-Nitrophenyl Octyl Ether (o-NPOE), dioctyl sebacate (DOS) and dibutyl phthalate (DBP) were obtained from TCI (Tokyo, Japan). Polyvinyl chloride (PVC) powder and trifluoroacetic acid were purchased from Sigma-Aldrich (St. Louis, MO, USA). All other reagents were of analytical grade. Deionised water was used to prepare and dilute all buffer and analyte solutions.

\subsection{Synthesis of CC3-R}

CC3-R was synthesised using a previously reported method [29]. Briefly, $20 \mathrm{~mL}$ dichloromethane was added dropwise onto $1.0 \mathrm{~g} \mathrm{1,3,5-triformylbenzene} \mathrm{in} \mathrm{a} \mathrm{two-necked} \mathrm{flask} \mathrm{without} \mathrm{stirring} \mathrm{at}$ room temperature, and $20 \mu \mathrm{L}$ trifluoroacetic acid was added as a catalyst. Within minutes, $20 \mathrm{~mL}$ dichloromethane containing $1.0 \mathrm{~g}(R, R)$-1,2-diaminocyclohexane was dripped slowly into the mixture. After reaction for $72 \mathrm{~h}$ at room temperature, white crystals were present on the wall of the flask, which were filtered and rinsed with ethanol/dichloromethane $(95: 5 \mathrm{v} / \mathrm{v})$.

\subsection{Preparation of Enantioselective Membrane Electrodes}

To prepare the PVC membranes, PVC powder, plasticiser (o-NPOE), and CC3-R were added to $3 \mathrm{~mL}$ tetrahydrofuran and stirred to form a transparent solution [40]. This was poured onto a glass sheet and volatilised for $24 \mathrm{~h}$ to form a semitransparent film $\sim 0.5 \mathrm{~mm}$ thick. The obtained film was incised into an appropriately sized disc and assembled using a PVC tube, which was subsequently filled with $0.1 \mathrm{~mol} \cdot \mathrm{L}^{-1} \mathrm{KCl}$ as an internal reference solution. A silver chloride electrode was applied as an internal reference electrode, and a saturated calomel electrode was utilised as a reference electrode. For comparison, a CC3-S-modified membrane electrode was prepared in the same way. The overall strategy for enantioselective potentiometric sensor fabrication is depicted in Scheme 1. 


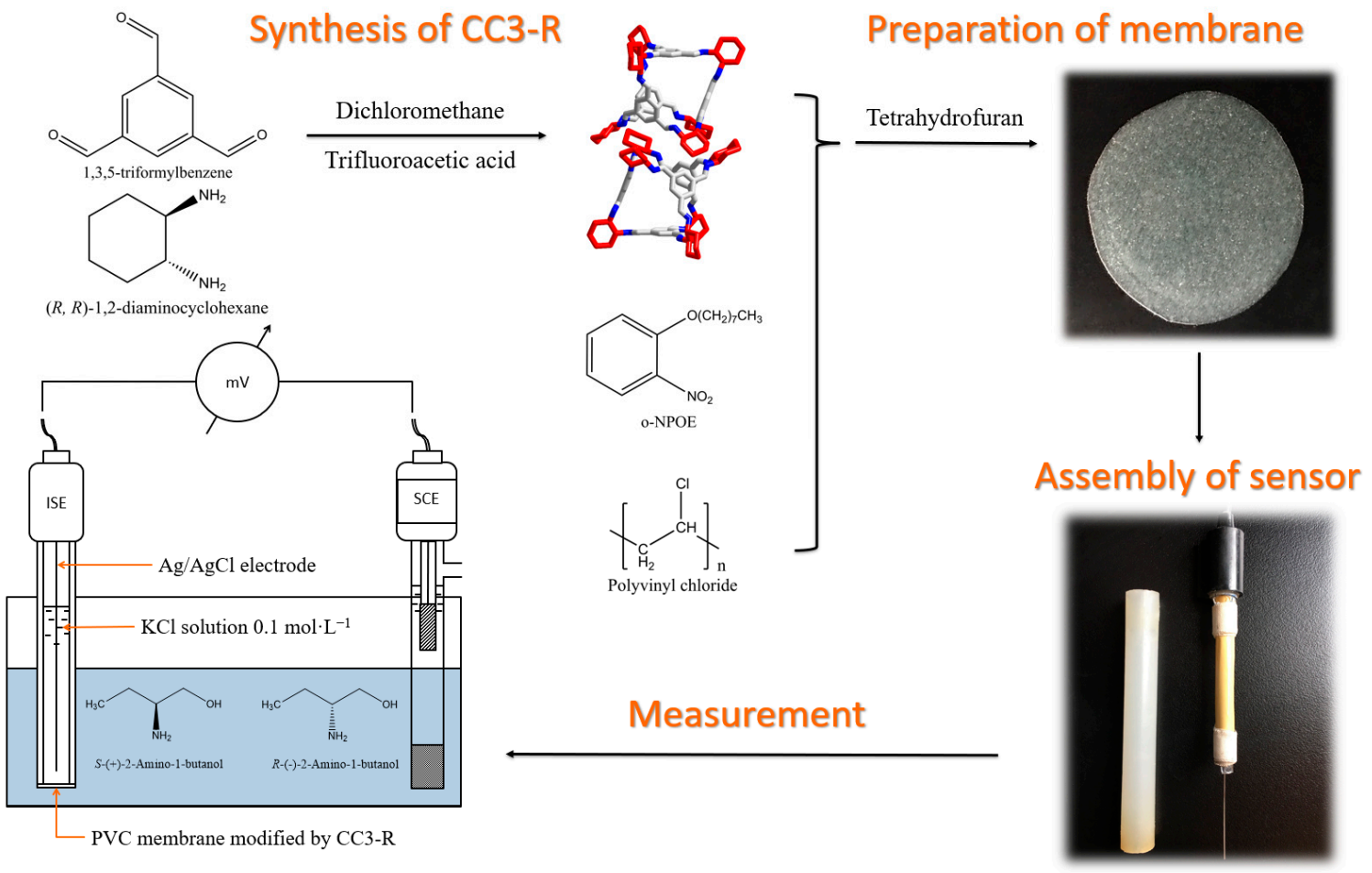

Scheme 1. Schematic illustration of enantioselective potentiometric sensor fabrication.

\subsection{Potentiometric Measurement}

The direct potentiometric method was applied to measure the potential value of each $S / R$-2-amino-1-butanol solution at different molar concentrations $\left(1.0 \times 10^{-6}\right.$ to $\left.1.0 \times 10^{-1} \mathrm{~mol} \cdot \mathrm{L}^{-1}\right)$ and mixing solution with different molar ratios $(S / R=1: 0,2: 1,1: 1,1: 2$, and 0:1). A Model PHS-3C pH meter (Leici, Shanghai, China) was used for potentiometric and $\mathrm{pH}$ measurements, and all potentiometric measurements were performed during stirring at room temperature. Before measurement, membrane electrodes were soaked in S-2-amino-1-butanol solution $\left(1.0 \times 10^{-3} \mathrm{~mol} \cdot \mathrm{L}^{-1}\right)$ for $24 \mathrm{~h}$.

A revised separate solution method was used to calculate the enantioselectivity coefficient $\left(\log K_{S, R}^{\text {Pot }}\right)$ with the following formula:

$$
\log K_{S, R}^{P o t}=\frac{E_{R}-E_{S}}{D}
$$

where $E_{R}$ and $E_{S}$ are the potentials of $0.1 \mathrm{~mol} \cdot \mathrm{L}^{-1} R$ - and $S$-2-amino-1-butanol solutions, respectively, and $D$ is the slope of the response curve of $S$-2-amino-1-butanol.

\section{Conclusions}

The chiral porous organic cage CC3-R proved to be a useful chiral selector for the modification of PVC membrane electrodes to generate enantioselective potentiometric sensors. The optimised membrane electrode containing $3 \mathrm{wt} \%$ CC3-R exhibited enantiomeric recognition toward S-2-amino-1-butanol over $R$-2-amino-1-butanol $\left(\log K_{S, R}^{P o t}=-0.98\right)$ with acceptable sensitivity, and a near-Nernst response of $25.8 \pm 0.3 \mathrm{mV} /$ decade toward S-2-amino-1-butanol at $\mathrm{pH} 9.0$. 
Author Contributions: Conceptualization, Q.-E.C. and L.-M.Y.; Methodology, A.-H.D.; Writing-Original draft preparation, B.-J.W.; Writing-Review and editing, J.-H.Z. and S.-M.X.

Funding: This research was funded by the National Nature Science Foundation of China (No. 21665028, No. 21265026, and No. 21465025).

Conflicts of Interest: The authors declare no conflict of interest.

\section{References}

1. Duan, A.H.; Wang, B.J.; Xie, S.M.; Zhang, J.H.; Yuan, L.M. A chiral, porous, organic cage-based, enantioselective potentiometric sensor for 2-aminobutanol. Chirality 2017, 29, 172-177. [CrossRef] [PubMed]

2. Xu, L.; Yang, Y.Y.; Wang, Y.Q.; Gao, J.Z. Chiral salen Mn(III) complex-based enantioselective potentiometric sensor for L-mandelic acid. Anal. Chim. Acta 2009, 653, 217-221. [CrossRef] [PubMed]

3. Chen, Y.; Chen, L.; Bi, R.L.; Xu, L.; Liu, Y. A potentiometric chiral sensor for 1-Phenylalanine based on crosslinked polymethylacrylic acid-polycarbazole hybrid molecularly imprinted polymer. Anal. Chim. Acta 2012, 754, 83-90. [CrossRef] [PubMed]

4. Stefan-van, S.R.I.; Nhlapo, N.S.; Staden-van, J.F.; Aboul-Enein, H.Y. Enantioanalysis of (-)butaclamol using vancomycin and teicoplanin as chiral Selectors. Comb. Chem. High Throughput Screen. 2010, 13, 690-693. [CrossRef]

5. Zhou, Y.X.; Nagaoka, T.; Yu, B.; Levon, K. Chiral ligand exchange potentiometric aspartic acid sensors with polysiloxane films containing a chiral ligand N-carbobenzoxy-aspartic acid. Anal. Chem. 2009, 81, 1888-1892. [CrossRef]

6. Stefan-van, S.R.I.; Staden-van, J.F.; Aboul-Enein, H.Y. Macrocyclic antibiotics as chiral selectors in the design of enantioselective, potentiometric membrane electrodes for the determination of S-flurbiprofen. Anal. Bioanal. Chem. 2009, 394, 821-826. [CrossRef]

7. Yin, X.L.; Ding, J.J.; Zhang, S.; Kong, J.L. Enantioselective sensing of chiral amino acids by potentiometric sensors based on optical active polyaniline films. Biosens. Bioelectron. 2006, 21, 2184-2187. [CrossRef]

8. Ozoemena, K.I.; Stefan, R.I. Enantioselective potentiometric membrane electrodes based on $\alpha-$, $\beta-$ and $\gamma$-cyclodextrins as chiral selectors for the assay of l-proline. Talanta 2005, 66, 501-504. [CrossRef]

9. Rat'ko, A.A.; Stefan, R.I.; Staden-van, J.F.; Aboul-Enein, H.Y. Macrocyclic antibiotics as chiral selectors in the design of enantioselective, potentiometric membrane electrodes for the determination of L- and D-enantiomers of methotrexate. Talanta 2004, 64, 145-150. [CrossRef]

10. Hui, M.D.; Yang, Y.H.; Li, B.J.; Pan, F.; Zhu, G.Z.; Zeller, M.; Yuan, D.Q.; Wang, C. Targeted synthesis of a large tria zine-based [4+6] organic molecular cage: Structure, porosity and gas separation. Chem. Commun. 2015, 51, 1976-1979.

11. Zhang, G.; Presly, O.; White, F.; Oppel, I.M.; Mastalerz, M. A permanent mesoporous organic cage with an exceptionally high surface area. Angew. Chem. Int. Ed. 2014, 53, 1516-1520. [CrossRef] [PubMed]

12. Zhang, G.; Mastalerz, M. Organic cage compounds-From shape-persistency to function. Chem. Soc. Rev. 2014, 43, 1934-1947. [CrossRef] [PubMed]

13. Liu, M.; Little, M.A.; Jelfs, K.E.; Jones, J.T.A.; Schmidtmann, M.; Chong, S.Y.; Hasell, T.; Cooper, A.I. Acidand base-stable porous organic cages: Shape persistence and $\mathrm{pH}$ stability via post-synthetic "tying" of a flexible amine cage. J. Am. Chem. Soc. 2014, 136, 7583-7586. [CrossRef] [PubMed]

14. Hasell, T.; Miklitz, M.; Stephenson, A.; Little, M.A.; Chong, S.Y.; Clowes, R.; Chen, L.J.; Holden, D.; Tribello, G.A.; Jelfs, K.E.; et al. Porous organic cages for sulfur hexafluoride separation. J. Am. Chem. Soc. 2016, 138, 1653-1659. [CrossRef] [PubMed]

15. Mastalerz, M.; Schneider, M.W.; Oppel, I.M.; Presly, O. A salicylbisimine cage compound with high surface area and selective $\mathrm{CO}_{2} / \mathrm{CH}_{4}$ adsorption. Angew. Chem. Int. Ed. 2011, 50, 1046-1051. [CrossRef] [PubMed]

16. Jin, Y.H.; Voss, B.A.; Jin, A.; Long, H.; Noble, R.D.; Zhang, W. Highly $\mathrm{CO}_{2}$-selective organic molecular cages: What determines the $\mathrm{CO}_{2}$ selectivity. J. Am. Chem. Soc. 2011, 133, 6650-6658. [CrossRef] [PubMed]

17. Mitra, T.; Wu, X.F.; Clowes, R.; Jones, J.T.A.; Jelfs, K.E.; Adams, D.J.; Trewin, A.; Bacsa, J.; Steiner, A.; Cooper, A.I. A soft porous organic cage crystal with complex gas sorption behavior. Chem. Eur. J. 2011, 17, 10235-10240. [CrossRef] [PubMed] 
18. Zhang, J.H.; Xie, S.M.; Wang, B.J.; He, P.G.; Yuan, L.M. A homochiral porous organic cage with large cavity and pore windows for the efficient gas chromatography separation of enantiomers and positional isomers. J. Sep. Sci. 2018, 41, 1385-1394. [CrossRef]

19. Zhang, J.H.; Zhu, P.J.; Xie, S.M.; Zi, M.; Yuan, L.M. Homochiral porous organic cage used as stationary phase for open tubular capillary electrochromatography. Anal. Chim. Acta 2018, 999, 169-175. [CrossRef]

20. Song, Q.L.; Jiang, S.; Hasell, T.; Liu, M.; Sun, S.J.; Cheetham, A.K.; Sivaniah, E.; Cooper, A.I. Porous organic cage thin films and molecular-sieving membranes. Adv. Mater. 2016, 28, 2629-2637. [CrossRef]

21. Xie, S.M.; Zhang, J.H.; Fu, N.; Wang, B.J.; Hu, C.; Yuan, L.M. Application of homochiral alkylated organic cages as chiral stationary phases for molecular separations by capillary gas chromatography. Molecules 2016, 21, 1466. [CrossRef] [PubMed]

22. Xie, S.M.; Zhang, J.H.; Fu, N.; Wang, B.J.; Chen, L.; Yuan, L.M. A chiral porous organic cage for molecular recognition using gas chromatography. Anal. Chim. Acta 2016, 903, 156-163. [CrossRef] [PubMed]

23. Zhang, J.H.; Xie, S.M.; Wang, B.J.; He, P.G.; Yuan, L.M. Highly selective separation of enantiomers using a chiral porous organic cage. J. Chromatogr. A 2015, 1426, 174-182. [CrossRef] [PubMed]

24. Kewley, A.; Stephenson, A.; Chen, L.J.; Briggs, M.E.; Hasell, T.; Cooper, A.I. Porous organic cages for gas chromatography separations. Chem. Mater. 2015, 27, 3207-3210. [CrossRef]

25. Mitra, T.; Jelfs, K.E.; Schmidtmann, M.; Ahmed, A.; Chong, S.Y.; Adams, D.J.; Cooper, A.I. Molecular shape sorting using molecular organic cages. Nat. Chem. 2013, 5, 276-281. [CrossRef] [PubMed]

26. Chen, L.J.; Reiss, P.S.; Chong, S.Y.; Holden, D.; Jelfs, K.E.; Hasell, T.; Little, M.A.; Kewley, A.; Briggs, M.E.; Stephenson, A.; et al. Separation of rare gases and chiral molecules by selective binding in porous organic cages. Nat. Mater. 2014, 13, 954-960. [CrossRef] [PubMed]

27. Xie, S.M.; Yuan, L.M. Recent progress of chiral stationary phases for separation of enantiomers in gas chromatography. J. Sep. Sci. 2017, 40, 124-137. [CrossRef]

28. Zhang, Y.; Xiong, Y.; Ge, J.; Lin, R.; Chen, C.; Peng, Q.; Wang, D.S.; Li, Y.D. Porous organic cage stabilised palladium nanoparticles: Efficient heterogeneous catalysts for carbonylation reaction of aryl halides. Chem. Commun. 2018, 54, 2796-2799. [CrossRef]

29. Kong, X.; Jiang, J.W. Amorphous porous organic cage membranes for water desalination. J. Phys. Chem. C 2018, 122, 1732-1740. [CrossRef]

30. Brutschy, M.; Schneider, M.W.; Mastalerz, M.; Waldvogel, S.R. Porous organic cage compounds as highly potent affinity materials for sensing by quartz crystal microbalances. Adv. Mater. 2012, 24, 6049-6052. [CrossRef]

31. Bojdys, M.J.; Briggs, M.; Jones, J.T.A.; Adams, D.J.; Chong, S.Y.; Schmidtmann, M.; Cooper, A.I. Supramolecular engineering of intrinsic and extrinsic porosity in covalent organic cages. J. Am. Chem. Soc. 2011, 133, 16566-16571. [CrossRef] [PubMed]

32. Tozawa, T.; Jones, J.T.A.; Swamy, S.I.; Jiang, S.; Adams, D.J.; Shakespeare, S.; Clowes, R.; Bradshaw, D.; Hasell, T.; Chong, S.Y.; et al. Porous organic cages. Nat. Mater. 2009, 8, 973-978. [CrossRef] [PubMed]

33. Yamamoto, C.; Yashima, E.; Okamoto, Y. Structural analysis of amylose tris(3,5-dimethylphenylcarbamate) by NMR relevant to its chiral recognition mechanism in HPLC. J. Am. Chem. Soc. 2002, 124, 12583-12589. [CrossRef] [PubMed]

34. Zhang, J.H.; Xie, S.M.; Chen, L.; Wang, B.J.; He, P.G.; Yuan, L.M. Homochiral porous organic cage with high selectivity for the separation of racemates in gas chromatography. Anal. Chem. 2015, 87, 7817-7824. [CrossRef] [PubMed]

35. Goncalves, R.S.B.; Da-Silva, E.T.; De-Souza, M.V.N. An environmentally friendly, scalable and highly efficient synthesis of (S,S)-Ethambutol, a first line drug against tuberculosis. Lett. Org. Chem. 2015, 12, 478-481. [CrossRef]

36. Dobrikov, G.M.; Valcheva, V.; Stoilova-Disheva, M.; Momekov, G.; Tzvetkova, P.; Chimov, A.; Dimitrov, V. Synthesis and in vitro antimycobacterial activity of compounds derived from (R)- and (S)-2-amino-1-butanol-The crucial role of the configuration. Eur. J. Med. Chem. 2012, 48, 45-56. [CrossRef] [PubMed]

37. Dobrikov, G.M.; Valcheva, V.; Nikolova, Y.; Ugrinova, I.; Pasheva, E.; Dimitrov, V. Efficient synthesis of new (R)-2-amino-1-butanol derived ureas, thioureas and acylthioureas and in vitro evaluation of their antimycobacterial activity. Eur. J. Med. Chem. 2013, 63, 468-473. [CrossRef] 
38. Dobrikov, G.M.; Valcheva, V.; Nikolova, Y.; Ugrinova, I.; Pasheva, E.; Dimitrov, V. Enantiopure antituberculosis candidates synthesized from (-)-fenchone. Eur. J. Med. Chem. 2014, 77, 243-247. [CrossRef]

39. Horváth, V.; Takécs, T.; Horvai, G.; Huszthy, P.; Bradshaw, J.S.; Izatt, R.M. Enantiomer-Selectivity of ion-selective electrodes based on a chiral crown-ether ionophore. Anal. Lett. 1997, 9, 1591-1609. [CrossRef]

40. Moody, G.J.; Oke, R.B.; Thomas, J.D.R. A calcium-sensitive electrode based on a liquid ion exchanger in a poly(vinyl chloride) matrix. Analyst 1970, 95, 910-918. [CrossRef]

Sample Availability: Not available.

(C) 2019 by the authors. Licensee MDPI, Basel, Switzerland. This article is an open access article distributed under the terms and conditions of the Creative Commons Attribution (CC BY) license (http:/ / creativecommons.org/licenses/by/4.0/). 